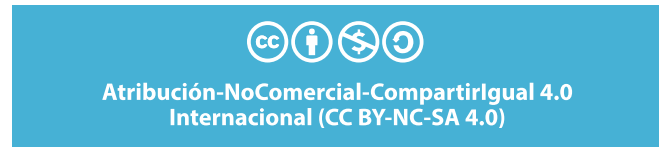

DOI: http://dx.doi.org/10.20983/reij.2021.2.2
Roberto Carlos Fonseca Luján ${ }^{1}$

FECHA DE ACEPTACIÓN: 27 de enero 2021

\title{
CONSTRUCCIÓN DE UN CONCEPTO CONSTITUCIONAL DE DELITO CON BASE EN LOS PRINCIPIOS DE TAXATIVIDAD, PROPORCIONALIDAD Y DIGNIDAD
}

\author{
Construction of a Constitutional Concept of Crime based on the Principles of Non- \\ Vagueness, Proportionality and Dignity
}

\section{Resumen}

El artículo tiene como objetivo central proponer un concepto constitucional de delito construido con base en los principios constitucionales de taxatividad, proporcionalidad y dignidad de la persona. Este concepto es pertinente en el marco del diálogo entre la dogmática penal y constitucional que ocurre en el proceso actual de constitucionalización del ordenamiento. La metodología emplea el método sistemático, cuya aplicación permite relacionar los principios desarrollados por la interpretación constitucional de la Suprema Corte de Justicia de la Nación con las categorías penales generadas por la Teoría del Delito. El empleo del método sistemático conduce a identificar que las tres categorías de análisis de la Teoría del Delito (tipicidad, antijuridicidad y culpabilidad) tienen como correlatos constitucionales los principios de taxatividad, proporcionalidad y dignidad con los cuales forman parejas inseparables. Este estudio es original, porque no se encuentra en la doctrina penal nacional una exposición explícita de esas parejas. Se concluye proponiendo que un delito desde la perspectiva constitucional es toda conducta que reúne tres cualidades: es antijurídica, porque agrede un bien protegido constitucionalmente, de modo que su punición respeta la proporcionalidad; es típica, porque encuadra en un tipo penal definido taxativamente; y es culpable, porque es ejecutada libremente por una persona a la que se le reconoce dignidad.

Palabras clave: Teoría del Delito; tipicidad; proporcionalidad; culpabilidad.

\section{Abstract}

The general purpose of the article is to propose a constitutional concept of crime based on the constitutional principles of non-vagueness, proportionality and person's dignity. This concept is pertinent within the framework of the dialogue between criminal law and constitutional law. This dialogue occurs in the current process of constitutionalization of the system. The methodology uses the systematic method to relate the principles developed by the constitutional interpretation of the Mexican Supreme Court with the categories

1 Doctor en Derecho. Profesor en la Facultad de Derecho de la Universidad Nacional Autónoma de México. Candidato a Investigador Nacional en el Sistema Nacional de Investigadores del Consejo Nacional de Ciencia y Tecnología; rfonsecal@derecho.unam.mx orciD: https://orcid.org/0000-0003-0076-9576. 


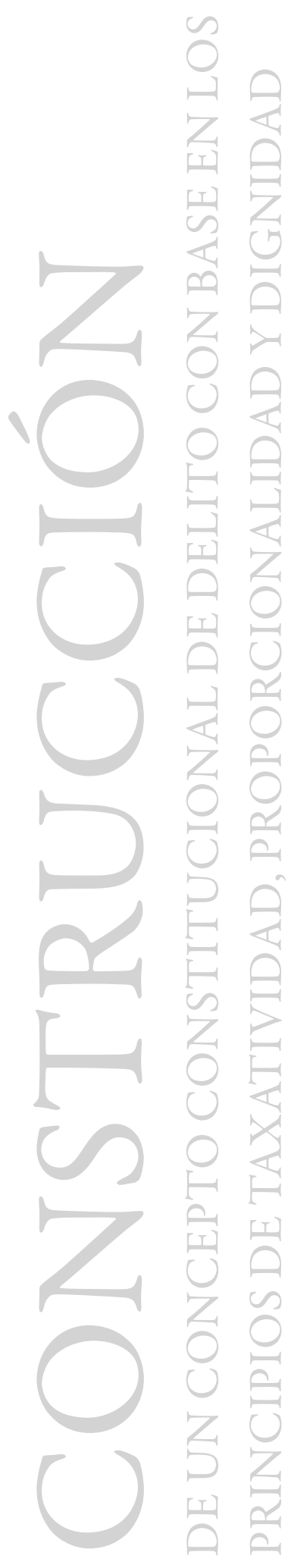

developed by the Theory of Crime. The use of systematic method leads to identify that the three categories of analysis of the Theory of Crime (criminal definition, unlawfulness and culpability) have as constitutional correlates the principles of non-vagueness, proportionality and dignity, with which they form inseparable pairs. This study is original because an explicit exposition of these couples is not found in the national criminal doctrine. The conclusion proposes that a crime from the constitutional perspective is any conduct that has three qualities: it is unlawful because it attacks a constitutionally protected value, so its punishment respects proportionality; it is illegal because it fits into a specifically defined crime; and it is guilty-minded because it is freely executed by a person to whom dignity is recognized.

Keywords: Theory of Crime; criminal definition; proportionality; culpability.

\section{Introducción}

a relación entre derecho penal y la Constitu-
ción ha sido evidente desde los orígenes del
Estado contemporáneo. En el ascenso del
constitucionalismo liberal durante el siglo
xviI, la garantía de los derechos del hombre y la división de poderes son objetivos que resultan inseparables de la legitimación y limitación del poder punitivo. El ideario recogido por Beccaria (2015) de un derecho penal sujeto a la legalidad, a la necesidad de la pena y libre de tormentos cristaliza en los principios y garantías penales de los documentos fundantes del constitucionalismo, como la Declaración francesa de Derechos del Hombre y del Ciudadano, y el Bill of Rights estadounidense.

Esta relación entre derecho penal y la Constitución es un tema ampliamente establecido en la literatura jurídica. Por un lado, poniendo énfasis en el texto constitucional, la doctrina se ha ocupado del estudio de las decisiones en materia criminal previstas en el articulado del texto fundamental, que tienen la forma de derechos, 
garantías y límites para el poder punitivo del Estado, y conforman lo que García Ramírez (2019) denomina "sistema penal constitucional” (p. 145). El estudio de estas decisiones, se ha denominado por autores como Ojeda Velázquez (2005) y Hernández-Romo Valencia (2020) como Derecho constitucional penal.

Por otro lado, poniendo énfasis en el estudio de la parte general del derecho penal, la dogmática ha estudiado el desarrollo de los principios penales - como intervención mínima o proporcionalidad-, que implícita o explícitamente pueden desprenderse de los preceptos constitucionales. Estos principios conforman lo que Arroyo Zapatero (1987) y Aguado Correa (1999), entre otros, denominan "programa penal de la Constitución", cuyo estudio se identifica como Derecho penal constitucional (Quintero Olivares \& Jaria i Manzano, 2015). Como es claro, ambos enfoques son complementarios.

El presente artículo se enmarca en este diálogo entre la dogmática penal y constitucional, yendo más allá de las aserciones comunes sobre los principios constitucionales del sistema penal, que se exponen al estudiar los derechos y garantías penales o al comienzo de un curso de la parte general del derecho penal. El método aplicado es el sistemático, que permite relacionar los principios acuñados por la interpretación constitucional con las categorías de la Teoría del Delito. Esta sistematización de la relación entre los principios constitucionales y el delito conduce a la proposición de lo que otra doctrina (Vives Antón, 1996, pp. 92 y ss.; Carbonell Mateu, 1999, pp. 21 y ss.) ya ha identificado como "concepto constitucional de delito".

De este modo, el método sistemático lleva a establecer las interrelaciones entre los principios identificados por la interpretación constitucional y las categorías de la Teoría del Delito. A partir de esta sistematización, se construye el concepto identificando los aspectos comunes a todo objeto que, a la luz de la interpretación constitucional, ha de contar como delito en el sistema jurídico mexicano. Este "concepto constitucional de delito", en el marco de la constitucionalización de todo el ordenamiento que se vive en la actualidad, cobra particular relevancia, pudiendo, incluso, tenerse en cuenta en las decisiones operativas y en la argumentación de casos concretos. Esta perspectiva no ha de sustituir, sino controlar, la delimitación del concepto jurídico-penal de delito.

\section{Constitucionalización de la Teoría del Delito}

En la doctrina constitucional contemporánea, se admite de manera generalizada que los sistemas jurídicos del mundo europeo continental y latinoamericano han experimentado en las últimas décadas un proceso de "constitucionalización" (Guastini, 2001, pp. 153 y ss.; Comanducci, 2009; Car- 
bonell, \& Sánchez Gil, 2011; Ortega García, 2013). Esta constitucionalización del ordenamiento jurídico ha abarcado al derecho penal, como ha estudiado Cote-Barco (2008), impactando en la comprensión de conceptos penales fundamentales como el de bien jurídico (Alonso Álamo, 2009) o promoviendo la interpretación de los tradicionales principios limitantes del ius puniendi (ultima ratio, intervención mínima u ofensividad), de acuerdo con las categorías estructurales puestas en boga por las teorías principialistas del neoconstitucionalismo, como hace Fernández (2019).

Evidentemente, el texto de la Constitución no define qué es un delito. ${ }^{2}$ Inclusive, puede sostenerse que a la Constitución de ninguna manera le corresponde definir qué es un delito. Sin embargo, a partir de la Constitución sí pueden reconstruirse las pautas para el control de lo que se puede definir como delito en el sistema. Esta reconstrucción la realiza la jurisprudencia constitucional que propiamente puede no hacer dogmática penal, pero sí establece conceptos que necesariamente han de influir en la doctrina nacional. Esto es así porque esos conceptos de origen jurisprudencial, en tanto desarrollan principios

2 Sin embargo, el texto constitucional sí menciona dos de las categorías de análisis de la Teoría del Delito en los artículos 19 y 20. Ahí se menciona el "tipo penal”, que remite a la categoría de la tipicidad, y la "culpabilidad", que remite por supuesto a ese aspecto. Esto se complementa con los numerales 14 y 16 constitucionales. Se agradece a uno de los dictaminadores del artículo por esta observación. propios del catálogo de derechos constitucionales, resultan de aplicación obligatoria en todas las ramas del derecho y por todas las autoridades, según la reforma al artículo $1^{\circ}$ constitucional de 2011. De este modo, en México, tras 2011, una Teoría del Delito que pretenda ser adecuada al derecho nacional, necesariamente ha de incorporar esos principios constitucionales de desarrollo jurisprudencial.

Como es bien sabido, la Teoría estándar del Delito desarrollada por la dogmática penal ha construido un modelo que analiza el concepto de delito en tres categorías básicas: tipicidad, antijuridicidad y culpabilidad. De acuerdo con un método sistemático, estas categorías se "constitucionalizan" cuando su contenido se pone en relación con lo que constitucionalmente implica cada una. De esta manera, el desarrollo de esta Teoría del Delito "constitucionalizada" relaciona las categorías penales con los conceptos y principios desarrollados por la interpretación constitucional del máximo tribunal del país. Este procedimiento, que enriquece la dogmática penal con la perspectiva de la dogmática constitucional, propone la construcción de conceptos constitucionales de tipicidad, antijuridicidad y culpabilidad. Estos conceptos resultan ser robustecidos, en tanto cuentan con el respaldo de la fuerza normativa de la Constitución.

Este desarrollo es de importancia, porque construir este modelo de Teoría del 
Delito constitucionalizada es útil para confrontar algunos de los principales desafíos que enfrenta la Teoría del Delito contemporánea. Entre estos desafíos están, por un lado, las críticas desde puntos de vista externos a la dogmática, que ponen en entredicho o niegan abiertamente la utilidad científica de la Teoría del Delito, además de denunciar que los conceptos de la parte general funcionan en el discurso jurídico como meras racionalizaciones. Entre estos desafíos están, por ejemplo, los comentarios deterministas contra el concepto material de culpabilidad inspirados en las neurociencias que, como reseña Feijoo Sánchez (2012), al pretender explicar todo proceso mental en términos biológico-causales, niegan la capacidad de libertad del ser humano y, con ella, la posibilidad de responsabilizar a los sujetos de sus actos (pp. 215 y ss.). Igualmente, la negación desde distintas perspectivas empíricas de las funciones preventivas de la pena. También, el llamado abierto a abandonar la Teoría del Delito que llegó a formular un pragmatismo procesal malentendido durante el tránsito al sistema acusatorio (Dondé Matute, 2012).

Paralelamente, se considera que la constitucionalización de los conceptos de la Teoría del Delito es una vía pertinente para contener el principal desafío a la teoría que se plantea desde el punto de vista interno. La deriva hacia un funcionalismo normativista radical, que hace a un lado las cuestiones sustantivo-valorativas que tradicionalmente han atañido al derecho penal de herencia liberal, para sostener como propósito central de la pena la garantía de la "identidad normativa" de la sociedad (Jakobs, 1996, p. 15; 2004, p. 75).

Frente a ese normativismo, las posiciones plausibles en la dogmática penal contemporánea se inclinan por sostener que los fines del sistema de derecho penal deben coincidir con los de la política criminal en un Estado de derecho. De modo que la propia dogmática del delito debe empaparse de las decisiones valorativas propias de esa política, como proponen Roxin (2000, p. 49) o Cruz Bolívar (2001). Esta política criminal, como es claro, debe, a su vez, inscribirse en los fines básicos del Estado de derecho constitucional, que son la protección y garantía de los derechos declarados constitucionalmente. Esta necesaria correlación entre los fines del sistema penal y los del constitucional, mediando la política criminal, da las bases para la constitucionalización de las categorías del derecho penal; que no es otra cosa más que su completa determinación con base en una perspectiva sistemática conforme con la Constitución.

No se trata aquí únicamente de hacer manifiesta la obviedad de que el derecho penal no puede ir en contra del derecho constitucional. Más bien, se trata de afirmar que la propia Constitución ha de ser el fundamento sustantivo y material del de- 
recho penal (Donini, 2001; Durán Migliardi, 2013), así como del método y sentido de la dogmática (Arroyo Zapatero, 1987, p. 99; Carbonell Mateu, 1999). De esta manera, el contenido del derecho penal y procesal no solo ha de verse limitado por las normas constitucionales y su interpretación, sino que también debe encontrar, según Quintero Olivares \& Jaria i Manzano (2015), un “anclaje positivo” en la Constitución, de modo que las normas constitucionales continúen y se desplieguen en el derecho penal (p. 8).

\section{Parejas conceptuales en la Teoría consti- tucional del Delito}

El desarrollo de la propuesta de sistematización aquí planteada parte de identificar que las tres categorías centrales de la teoría del delito (tipicidad, antijuridicidad y culpabilidad) tienen como correlatos constitucionales los principios de taxatividad, proporcionalidad y dignidad, según ya ha sido sugerido por Rodríguez Mourullo (2003). En la teoría del delito constitucional, estas nociones forman parejas que resultan inseparables. A continuación se hará una revisión mínima del contenido de cada una de estas parejas, cuyo desarrollo sistemático se echa en falta en la doctrina nacional.

\section{Tipicidad-Taxatividad}

La pareja tipicidad-taxatividad es, probablemente, la más familiar para la dogmática penal nacional, en tanto surge del propio Principio de Legalidad Penal: la máxima liberal de que no hay pena ni delito sin ley o nullum crimen nulla poena sine lege (Inzunza Cázares, 2009, pp. 29 y 62). La doctrina coincide en señalar que el Principio de Legalidad abarca cuatro componentes básicos: reserva de ley escrita (lex scripta); taxatividad o mandato de determinación (lex certa); irretroactividad (lex praevia) y prohibición de analogía (lex stricta) (Bacigalupo, 1999, pp. 44-45; Inzunza Cázares, 2009, pp. 65 y ss.). En específico, la taxatividad requiere que las leyes que establezcan delitos y penas deben cumplir determinadas cualidades, como la completitud, la precisión y la claridad.

Al respecto, Ferrajoli (1995) sugiere que la taxatividad dispone para el legislador penal tres mandatos: a) emplear términos de "extensión determinada" para las descripciones de las figuras delictivas, de modo que puedan emplearse "como predicados «verdaderos de los» hechos empíricos por ellos denotados"; b) emplear "palabras no vagas ni valorativas, sino lo más claras y precisas posible", de modo que pueda ser “connotada su intención”; y c) eliminar "las antinomias semánticas" del texto legal o, en último caso, prever "normas para su solución” (p. 121). En sentido similar, se 
apunta que el principio de "máxima taxatividad legal" obliga a que la "criminalización primaria" se realice "con la mayor precisión técnica posible”, evitando, por ejemplo, la remisión a "conceptos vagos o valorativos de dudosa precisión" (Zaffaroni, Alagia, \& Slokar, 2002, pp. 116-117).

La jurisprudencia constitucional mexicana ha desarrollado ampliamente este Principio de Taxatividad en sus decisiones, derivando la exigencia de taxatividad de la garantía de estricta legalidad en materia penal que se señala en el artículo 14 del texto constitucional. La doctrina consolidada al respecto, se ha expresado recientemente, por ejemplo, en la sentencia del Pleno a la Acción de inconstitucionalidad 51/2018, que controvierte diversas disposiciones penales de San Luis Potosí, que criminalizan la conducción imprudente de vehículos por el empleo de distractores (teléfonos celulares). En el Considerando Quinto de la sentencia, se define el principio, lo que por su importancia se transcribe:

En materia penal, existe una exigencia de racionalidad lingüística que es conocida precisamente como principio de taxatividad. Este principio constituye un importante límite al legislador penal en un Estado democrático de derecho en el que subyacen dos valores fundamentales: la certeza jurídica y la imparcialidad en la aplicación del derecho. Se traduce en un auténtico deber constitucional del legislador según el cual está obligado a formular en términos precisos los supuestos de hecho de las normas penales. En otros términos, el principio de taxatividad puede definirse como la exigencia de que los textos en los que se recogen las normas sancionadoras describan con suficiente precisión qué conductas están prohibidas y qué sanciones se impondrán a quienes incurran en ellas (Acción de inconstitucionalidad 51/2018).

Teniendo en cuenta la distinción teórica generalizada actualmente entre las "reglas" y los "principios" (Alexy, 1993, pp. 86-87), la jurisprudencia constitucional ha tendido a interpretar la taxatividad como un principio, es decir, como una norma cuyo cumplimiento admite grados. En tal sentido, en el mismo Considerando Quinto de la Acción de inconstitucionalidad señalada, se establece que:

La precisión de las disposiciones es una cuestión de grado; por ello, lo que se busca con este tipo de análisis no es validar las normas si y sólo si se detecta la certeza absoluta de los mensajes del legislador, ya que ello es lógicamente imposible, sino más bien lo que se busca es que el grado de imprecisión sea razonable, es decir, que el precepto sea lo suficientemente preciso como para declarar su validez, en tanto se considera que el mensaje legislativo cumplió esencialmente 
su cometido dirigiéndose al núcleo esencial de casos regulados por la norma [...] el otro extremo sería la imprecisión excesiva o irrazonable, es decir, un grado de indeterminación tal que provoque en los destinatarios confusión o incertidumbre por no saber a ciencia cierta cómo actuar ante la nueva norma jurídica; la certeza jurídica y la imparcialidad en la aplicación del derecho, se insiste, son los valores subyacentes al principio de taxatividad (Acción de inconstitucionalidad 51/2018).

El contenido del Principio de Taxatividad ha sido también desarrollado por la Corte Interamericana de Derechos Humanos en su jurisprudencia, en la cual se vinculan estrechamente los Principios de Legalidad Penal, Tipicidad y Taxatividad. En tal sentido, en la sentencia del Caso Usón Ramírez, se recuerda que:

la Corte ha declarado en su jurisprudencia previa que en la elaboración de los tipos penales es preciso utilizar términos estrictos y unívocos, que acoten claramente las conductas punibles, dando pleno sentido al principio de legalidad penal. Esto implica una clara definición de la conducta incriminada, la fijación de sus elementos y el deslinde de comportamientos no punibles o conductas ilícitas sancionables con medidas no penales [...] Así, la tipificación de un delito debe formularse en forma expresa, precisa, taxativa y previa, más aún cuando el derecho penal es el medio más restrictivo y severo para establecer responsabilidades respecto de una conducta ilícita, teniendo en cuenta que el marco legal debe brindar seguridad jurídica al ciudadano (Párr. 55).

La pareja tipicidad-taxatividad tiene bastante impacto en la práctica. La mayoría de las discusiones sobre la constitucionalidad de los tipos penales generalmente se reconducen al ámbito de la taxatividad. Por ejemplo, se pueden mencionar las decisiones del Pleno sobre la inconstitucionalidad del delito de ultrajes a la autoridad, antes previsto en el artículo 287 del Código Penal para el Distrito Federal. En estas sentencias, por la indefinición e indeterminación del verbo "ultrajar", el Pleno consideró que en el tipo "no quedaban debidamente definidos cuáles actos o conductas (palabras, gestos o hechos) que causan un agravio, propio del ultraje, rebasan el umbral necesario para ser sancionados” (Amparo Directo en Revisión 2255/2015; Amparo Directo en Revisión 4436/2015).

De esta manera, la Teoría del Delito constitucional no puede entender la tipicidad sin la taxatividad. Solo hay tipicidad cuando hay taxatividad. Algo no puede ser delito en el sistema constitucional si su tipicidad es no taxativa, es decir, si su tipo penal muestra características como 
la indeterminación o la imprecisión en un grado excesivo o irrazonable.

\section{Antijuridicidad-Proporcionalidad}

De manera general, la Teoría del Delito sostiene que la antijuridicidad en sentido material de una conducta deviene de su dañosidad; de que lesiona o pone en peligro un bien jurídico de manera significativamente intolerable. La exigencia de antijuridicidad material supone un límite al poder punitivo, porque solo habilita la imposición de pena cuando la conducta que se juzga presenta ese carácter lesivo: compromete sensiblemente un bien jurídico protegido; además, ha de hacerlo de manera injusta. Si la conducta no lastima ningún bien, o aun haciéndolo aparece como justificada, resulta ilegítima su sanción.

En el elenco de los principios constitucionales esta idea de antijuridicidad se relaciona con el Principio de Proporcionalidad, que según enseña la dogmática constitucional tiene que ver básicamente con lo que Aguado Correa (1999), entre otros, identifica como "la prohibición del exceso" de parte del poder. Se admite que el poder público puede restringir bienes e intereses protegidos, como derechos de las personas; incluso, privar de su goce. Sin embargo, esas restricciones solo pueden hacerse en la medida estrictamente necesaria cuando sean indispensables para alcanzar otro fin legítimo. Esa es la idea básica de la proporcionalidad. Dado que el ejercicio del poder punitivo conlleva restricciones y puede conducir a privaciones de derechos de las personas, en los distintos momentos de su despliegue también debe ejercerse de modo proporcional.

Este Principio constitucional de Proporcionalidad o Prohibición del Exceso tiene distintos acomodos en la Teoría del Delito. Además de relacionarse intrínsecamente con la categoría de antijuridicidad y las causas de justificación, como se ha mencionado antes, aparece como un límite al programa de criminalización legislativo, ámbito en el cual se le relaciona con el Principio de Exclusiva Protección de Bienes Jurídicos (Alonso Álamo, 2009, p. 70). Igualmente, tiene acomodo en los momentos de determinación legislativa y de individualización judicial de la pena, escenarios en los que se habla de proporcionalidad de la pena o simplemente de proporcionalidad en sentido estricto (Aguado Correa, 1999; Cote-Barco, 2008). Más aún, en la doctrina penal constitucionalizada se observa una tendencia a "aglutinar" los tradicionales principios y límites del ius puniendi bajo el concepto del "principio de proporcionalidad en sentido amplio", según lo entiende la dogmática de los derechos fundamentales (Fernández, 2019, pp. 181-182).

La proporcionalidad, en sentido amplio, es la idea de proporcionalidad que se relaciona con los escrutinios de razonabilidad y constitucionalidad que los órganos de 
justicia constitucional han venido utilizando en las últimas décadas. La idea de proporcionalidad sugiere un límite que asegura la supremacía de los derechos constitucionales; este límite, recuerda Sánchez Gil (2017), se basa en la ya mencionada "prohibición de exceso en el ejercicio del poder", según la cual, cuando la acción estatal requiere restringir un bien que es contenido de un derecho fundamental, esto ha de hacerse "solo en la medida estrictamente indispensable" para alcanzar otro fin legítimo (p. 20).

Como es bien conocido, en la jurisprudencia constitucional mexicana la versión más sofisticada del escrutinio o Test de Proporcionalidad se desarrolla en las sentencias de la Primera Sala, por ejemplo, en los amparos 237/2014 y sucesivos relativos al uso lúdico de cannabis sativa. En dichas decisiones se propone un análisis de constitucionalidad de toda medida legislativa que valora progresivamente cuatro aspectos: a) constitucionalidad de los fines perseguidos; b) idoneidad; c) necesidad; y d) proporcionalidad en sentido estricto o ponderación (Amparo en revisión 547/2018). Este escrutinio está influenciado por el modelo ponderativo desarrollado por la jurisprudencia y la doctrina alemanas con la formulación de Alexy (1993) como la más conocida, basada en su concepto de principios como "mandatos de optimización", cuyos conflictos han de resolverse atendiendo a las pautas de la "ley de colisión" (pp. 86, 89 y 90) o "ley de ponderación” (2016, pp. 1-11).

Hay que señalar que la propia Primera Sala ha planteado una distinción entre dicho Principio de Proporcionalidad en sentido amplio, según se entiende en el ámbito de los derechos fundamentales, y el Principio de Proporcionalidad de la pena, previsto en el artículo 22 constitucional. En diversas tesis aisladas, que se derivan del Amparo Directo en Revisión 85/2014, la Primera Sala plantea una interpretación sectorizada de lo que se entiende por proporcionalidad, al señalar que:

El término "proporcionalidad" es ambiguo, ya que puede predicarse del test de proporcionalidad en materia de derechos fundamentales, o de las penas, en términos del artículo 22 constitucional. Así, en el primer caso, lo que se analiza es una relación entre principios [cuyos conflictos] deben resolverse aplicando un test de proporcionalidad [...] En cambio, en el caso de la proporcionalidad de penas, regularmente se analiza una regla (el tipo penal de que se trate) frente a un principio constitucional (el principio de proporcionalidad establecido en el artículo 22 constitucional), con la finalidad de determinar si aquélla -la regla- satisface o no la exigencia del principio constitucional; concretamente, si la pena es acorde o no en relación con el bien jurídico afectado. En estos casos, es posible 
adoptar cualquier metodología encaminada a la justificación exigida por el artículo 22, dejando fuera, naturalmente, un análisis de proporcionalidad en materia de derechos fundamentales, dado que en este tipo de casos no se está ante la colisión de dos principios (Tesis 1a. CCCIX/2014, 10a.).

Como se aprecia, la Primera Sala parece confundir una parte (la interpretación específica de la proporcionalidad que configura una metodología de escrutinio o test para resolver conflictos entre principios constitucionales) con el todo (el Principio de Proporcionalidad en sentido amplio entendido como prohibición del exceso en el ejercicio del poder). De ahí que sostenga que, al discutir sobre la medida de la pena, no puede hablarse de escrutinio de proporcionalidad, porque no hay "colisión entre principios”. Cabe añadir que en esta decisión la Primera Sala reorienta su propia doctrina sobre el tema, que había expuesto pocos años antes en la sentencia del Amparo Directo en Revisión 181/2011. Precisamente, en las tesis aisladas derivadas de esta decisión de 2011 se asume la posición que luego se va a objetar en 2014, pues se valora la proporcionalidad de la pena del delito de secuestro exprés haciendo un análisis con base en las gradas del Test de Proporcionalidad, como legitimidad, idoneidad, necesidad y proporcionalidad en sentido estricto (Tesis: 1a. CCXII/2011, 9a.; Tesis: 1a. CCXIII/2011, 9a.; Tesis: 1a. CCXI/2011, 9a.; Tesis: $1 a$. CCX/2011, 9a.).

$\mathrm{Al}$ margen de estos vaivenes en la jurisprudencia de la Primera Sala, para los fines de esta exposición se considera necesario partir del sentido primario de la proporcionalidad como "prohibición del exceso”. En este sentido, no existe esa separación entre proporcionalidad penal y en materia de derechos fundamentales; al contrario, como ilustra Aguado Correa (1999), la idea de proporcionalidad nace en el derecho penal de la Ilustración y de ahí pasa durante el siglo xix europeo al derecho de policía y a otros ámbitos del derecho administrativo hasta asumirse como "principio general del Derecho público" y después como "principio general del ordenamiento jurídico". Es este el mismo Principio de Proporcionalidad, de origen penal, que es configurado ya en el siglo xx por el Tribunal Constitucional alemán, desde donde influye a Hispanoamérica.

De esta manera, para la Teoría del Delito constitucional, más que separar, lo que ha de hacerse es caracterizar la dimensión del Principio de Proporcionalidad que interesa, según si la incorporación del principio se hace en relación con la antijuridicidad o la punibilidad. En ambos escenarios, la proporcionalidad implica la medida de lo que resulta justo realizar, al ejercer el ius puniendi, en un Estado de derecho constitucional. Esta medida alude al qué tanto 
se debe criminalizar, limitando la libertad general de los ciudadanos, y al qué tanto se debe punir, limitando las libertades concretas de un ciudadano determinado, para alcanzar los fines constitucionalmente legítimos de un derecho penal orientado a la prevención general y especial. Este derecho a la libertad general, caracterizado desde la perspectiva de Alexy (1993) como una norma fundamental permisiva según la cual "toda acción (hacer u omisión) está permitida, a menos que esté prohibida por una norma jurídica formal y materialmente constitucional" (p. 337), se protege en el régimen constitucional mexicano, según ha expresado la Primera Sala, como un bien "genérico", caracterizado como "la libertad de realizar cualquier conducta que no perjudique a terceros" (Amparo en revisión 547/2018).

La criminalización, la creación de cualquier tipo penal, es una medida legislativa que implica restricciones a dicha libertad de la persona. En esa medida, el estudio constitucional de la proporcionalidad exige esclarecer desde el primer momento cuál es la finalidad que el legislador persigue con la criminalización de una determinada conducta. Esa finalidad, ha sostenido la dogmática penal, ha de ser la tutela de un bien jurídico. Este postulado de la protección de bienes jurídicos, se revigoriza cuando la Teoría del Delito constitucional muestra que la protección de un bien jurídico no es una mera raciona- lización, sino un mandato constitucional que debe reclamarse en cada caso típico y puede conducir a la inconstitucionalidad del tipo penal cuando se incumple.

Las pautas del análisis constitucional de proporcionalidad indican que puede ser finalidad legítima la protección de valores, intereses, bienes o principios. Dado esto, cada uno de los objetos valiosos para el derecho que la dogmática penal ha denominado bienes tutelados, para ser legítimos constitucionalmente, habrían de encontrar correlato con algún bien o valor congruente con el marco constitucional. De este modo, si no hay bien jurídico con anclaje constitucional en el fondo del tipo penal, la criminalización deviene en un ejercicio de poder inconstitucional. En un caso así, aun siendo típica, esa conducta no podría considerarse un delito en el sistema constitucional.

En un nivel posterior, identificado ese bien, aparece que la vía de protección tendría que ser necesaria; es decir, tendría que ser indispensable, de modo que no existan otras medidas alternativas igualmente idóneas que puedan afectar en menor grado la libertad de la persona. $\mathrm{Si}$ hay otras medidas, el ejercicio de poder punitivo deviene innecesario y, por tanto, ilegítimo. Eso es precisamente lo que se encuentra en los argumentos de la Primera Sala sobre la inconstitucionalidad de la prohibición penal absoluta del consumo de cannabis sativa (Tesis: 1a./J 10/2019, 
10a.). A juicio de la Primera Sala, en esos casos hay otras medidas legislativas que podrían proteger los bienes involucrados, sin intervenir ni limitar con tanta intensidad en el derecho a la libertad de las personas, como lo hace la prohibición absoluta y la criminalización.

La jurisprudencia de la Primera Sala aparece influenciada por la jurisprudencia de la Corte Interamericana, que ha empleado la estructura de la proporcionalidad para evaluar el apego a la Convención Americana de tipos penales nacionales, particularmente cuando el ámbito de lo sancionado penalmente representa una restricción a la libertad de expresión. Así, en la ya citada sentencia del Caso Usón Ramírez, se estudian sucesivamente respecto del tipo penal controvertido: la "finalidad legítima de acuerdo con la Convención”, la "idoneidad [...] para lograr la finalidad perseguida", la "necesidad" y, finalmente, la "estricta proporcionalidad de la medida" (Párrs. 49, 59 y ss.).

De esta manera, el análisis de proporcionalidad ofrece una estructura argumentativa que permite reclamar la inconstitucionalidad de la criminalización en un sentido sustantivo o material por la falta de identificación de un bien jurídico, cuya protección justifique el ejercicio del poder punitivo. Asimismo, aun existiendo un bien jurídico constitucional involucrado, la estructura argumentativa de la proporcionalidad permite reclamar la inconsti- tucionalidad del tipo penal cuando la criminalización resulta innecesaria.

En relación con esto, cabe referir que la sentencia del Pleno a la Acción de inconstitucionalidad 51/2018, antes mencionada, declara la invalidez de las normas penales controvertidas precisamente porque no se cumplen con exigencias relacionadas con la proporcionalidad. Aunque la argumentación del Pleno en esta decisión no menciona expresamente el concepto de proporcionalidad en sentido amplio, sí se presentan razones claramente relacionadas con este, como la idea de que la sanción penal debe ser la ultima ratio del Estado, e imponerse solo cuando resulta absolutamente necesaria. Textualmente, se señala en el Considerando Quinto:

El poder punitivo sólo debe ejercerse en la medida estrictamente necesaria para proteger los bienes jurídicos más importantes de los ataques más graves que los dañen o pongan en peligro. Por ello, debe constatarse la existencia de una absoluta necesidad de utilizar, en forma verdaderamente excepcional, medidas penales [...] El principio de mínima intervención implica que el derecho penal debe ser el último recurso de la política social del Estado para la protección de los bienes jurídicos más importantes frente a los ataques más graves que puedan sufrir. De ahí que la intervención del derecho penal en la vida social debe reducirse a 
lo mínimo posible. Dicho principio también denominado de ultima ratio, implica que las sanciones penales se deben limitar al círculo de lo indispensable, de manera tal que el castigo para las conductas lesivas a los bienes jurídicos que previamente se han considerado dignos de protección, se restrinja a aquellas modalidades de ataque más peligrosas [...] la criminalización de un comportamiento humano debe ser la última de las decisiones posibles en el espectro de sanciones que el Estado está en capacidad jurídica de imponer. Se entiende que la decisión de sancionar con una pena, que implica en su máxima drasticidad la pérdida de la libertad, es el recurso extremo al que puede acudir el Estado para reprimir un comportamiento que afecta los intereses sociales (Acción de inconstitucionalidad 51/2018).

Estos planteamientos coinciden con la doctrina llamada garantista; así, Ferrajoli (1995) apunta que "el principio de necesidad exige que se recurra a [la intervención punitiva] sólo como remedio extremo [porque] es la técnica de control social más gravosamente lesiva de la libertad y de la dignidad de los ciudadanos” (p. 465). De esta manera, la criminalización controlada por la proporcionalidad - particularmente por la exigencia estricta de absoluta necesidad de la pena- parte de la tesis de que toda figura típica implica una restricción a los derechos de libertad de la persona. En ejercicio de la libertad, cada individuo puede determinarse a realizar su plan de vida bajo la previsión, propia de la vida en sociedad, de que si encamina sus actos a afectar de manera injusta los bienes básicos de la vida social protegidos por la Constitución, es decir, si actúa antijurídicamente en un sentido material, enfrentará una respuesta institucional que podrá privarlo de su libertad o de otros bienes. Eso es la sanción. En el Estado de derecho corresponde a los legisladores determinar cuáles son esos ejercicios de libertad injustos, que serán sancionados. Sin embargo, en el Estado constitucional contemporáneo esas atribuciones están sujetas al mandato de razonabilidad o proporcionalidad, cuyo respeto lo controla el máximo tribunal del país, como guardián de la Constitución.

Este concepto constitucional de antijuridicidad enriquecido por la idea de proporcionalidad que se desarrolla, da bases para combatir el tan criticado expansionismo punitivo que la doctrina asocia principalmente con esos casos típicos en los que, por más que se busca, no aparece un bien jurídico tutelado; o bien, cuando sí se identifica un bien, la conducta criminalizada no lo lesiona ni lejanamente lo pone en peligro. En casos así, aun siendo típicas, esas conductas no deberían considerarse delitos en el sistema constitucional, pues la punición de conductas no antijurídicas 
aparece como desproporcionada, en tanto es innecesaria.

Con estas bases, en esta elaboración de una definición de delito a partir de los principios constitucionales, el primer aspecto lógico resulta ser la antijuridicidad material, cuya presencia condiciona cualquier posible tipicidad. En la determinación de qué objetos pueden ser un delito, primero tendría que identificarse cuál es el bien constitucionalmente protegido que resulta interferido o lesionado en su goce y por qué conductas, para luego pasar a su formulación típica, simplemente describiendo esa interferencia o lesión. De esta manera, en la Teoría del Delito constitucional, la idea de la proporcionalidad como límite al ius puniendi, se relaciona en un primer momento con la antijuridicidad material de la conducta típica, y en un momento posterior con la medida de la punibilidad.

\section{Culpabilidad-Dignidad}

Desde antes de la Reforma de 2011, el Pleno de la Suprema Corte de Justicia de la Nación (scjN) había sostenido que

en el ser humano hay una dignidad que debe ser respetada en todo caso, constituyéndose como un derecho absolutamente fundamental, base y condición de todos los demás, el derecho a ser reconocido y a vivir en y con la dignidad de la persona humana (Tesis: P. LXV/2009).
La Primera Sala ha abundado en el concepto, para dar una caracterización jurídica del mismo. En la jurisprudencia relativa, se señala textualmente:

la dignidad humana no es una simple declaración ética, sino que se trata de una norma jurídica que consagra un derecho fundamental a favor de la persona y por el cual se establece el mandato constitucional a todas las autoridades, e incluso particulares, de respetar y proteger la dignidad de todo individuo, entendida ésta -en su núcleo más esencial- como el interés inherente a toda persona, por el mero hecho de serlo, a ser tratada como tal y no como un objeto, a no ser humillada, degradada, envilecida o cosificada (Tesis 1a./J. 37/2016).

De manera elemental, ese sentido de dignidad se traduce en la práctica jurídica en un reclamo de trato: que a la persona se le dé el trato debido. Se respeta la dignidad cuando a cualquiera se le trata con el respeto que merece. Esto admite variadas interpretaciones; en el muy conocido planteamiento del imperativo categórico kantiano, la dignidad obliga a no instrumentalizar ni cosificar a la persona; a que siempre se le trate como un fin en sí mismo y no solamente como un medio (scjN, 2013, pp. 1-2). Desde una perspectiva contemporánea, puede afirmarse que a los seres humanos se les trata de manera dig- 
na cuando en el ejercicio del poder, como sugiere Dworkin (1989), se les trata "con consideración y respeto”; de modo considerado, como "seres humanos capaces de sufrimiento y de frustración”, y de forma respetuosa, como "seres humanos capaces de llegar a concepciones inteligentes de cómo han de vivir su vida, y de actuar de acuerdo con ellas" (pp. 388-389).

Para la Teoría del Delito constitucional es relevante sostener que este trato debido solo es compatible con un concepto material de culpabilidad, fundado sustantivamente en una tesis fuerte sobre la libertad y la autodeterminación humana. Este fundamento material, se corresponde con la concepción antropológica subyacente al aparato de los derechos humanos internacionales, que es el reconocimiento de todo ser humano como persona libre y digna (Náquira Riveros, 1995). De acuerdo con esta idea, en principio solo es admisible castigar a alguien por algo que ha decidido realizar libremente. Así, como coinciden Cote-Barco (2008, p. 130) y Rodríguez Mourullo (2003, p. 320), es contrario a la dignidad pretender punir a alguien por algo que no ha podido decidir, lo que es acorde con el componente de la exigibilidad de otra conducta.

Igualmente, lesiona la dignidad imponer penas por la personalidad del sujeto o por una manera de ser que - sin lesionar ningún bien jurídico- se podría valorar desde la perspectiva mayoritaria como in- adaptada o desviada. Lo mismo para las penas que pretenden corregir o remediar al sentenciado; como apunta Ferrajoli (1995):

cualquier tratamiento penal dirigido a la alteración coactiva de la persona adulta con fines de recuperación o de integración social [...] lesiona [...] la dignidad del sujeto tratado [y viola] el primer derecho de cada hombre que es la libertad de ser él mismo y de seguir siendo como es (p. 272).

La jurisprudencia constitucional ha desarrollado aspectos de este concepto de culpabilidad compatible con la idea de la dignidad en las tesis relativas a la distinción entre derecho penal del acto y derecho penal de autor. En particular, la Primera Sala sostiene con claridad que:

el derecho penal no puede sancionar la ausencia de determinadas cualidades o la personalidad, porque está limitado a juzgar actos [...] el derecho penal únicamente puede prohibir la comisión de conductas específicas (no la personalidad) [Asimismo, el] hecho de que la Constitución haya eliminado la posibilidad de que el sistema penal opere bajo la premisa de que alguien es desadaptado, fundamenta la convicción de que nuestro sistema se decanta por un derecho penal sancionador de delitos, no de personalidades. Así, el abandono del término "delincuente" también exhibe la 
intención del constituyente permanente de eliminar cualquier vestigio de un "derecho penal de autor", permisivo de la estigmatización de quien ha cometido un delito (Tesis: 1a./J. 21/2014, 10a.).

En complemento con lo anterior, se sostiene que el Estado ha abandonado toda intención declarada de "corregir" o "readaptar" al delincuente. $\mathrm{Al}$ asumirlo como un sujeto libre deja a su ámbito interno el cómo lidia con su hecho delictivo y con la pena. Según la Primera Sala:

el derecho penal del acto no justifica la imposición de la pena en una idea rehabilitadora, ni busca el arrepentimiento del infractor; lo asume como un sujeto de derechos y, en esa medida, presupone que puede y debe hacerse responsable por sus actos. Por ello, la forma en que el individuo lidia en términos personales con su responsabilidad penal, queda fuera del ámbito sancionador del Estado (Tesis: 1a./J. 19/2014, 10a.).

Hay que señalar que la culpabilidad también se relaciona intrínsecamente en la perspectiva constitucional con la proporcionalidad de la pena, ya no en el escenario de la antijuridicidad comentado antes, sino ahora en relación con la punibilidad. La culpabilidad funge como medida y como límite de la cantidad de pena que resulta proporcionado imponer a un autor concreto. Aquí se interrelacionan los tres principios: dignidad-culpabilidad-proporcionalidad, pues el denominado grado de culpabilidad que requiere la legislación procesal para individualizar la pena implica la valoración de la exigibilidad; esto es, qué tanto el autor del delito concebido como un sujeto libre pudo haber actuado de otro modo.

En la dogmática penal, se ha venido discutiendo en las últimas décadas este concepto material de culpabilidad sustentado en una concepción fuerte de libertad por considerarse simplemente que la posibilidad de autonomía - que el sujeto infractor haya podido no decidir no cometer el delito- es un asunto indemostrable empíricamente. Esto es más acentuado en las tesis deterministas inspiradas en las neurociencias, que simplemente niegan la posibilidad del libre albedrío como se ha entendido en la filosofía liberal. Esas concepciones son incompatibles con una Teoría del Delito orientada a principios constitucionales. En esta, como propone Roxin (1981, pp. 41 y ss.), el concepto de culpabilidad no solo ha de estar relacionado con la proporcionalidad y fungir como un "principio limitador de la pena"; también es imprescindible su vinculación con una afirmación normativa del Principio de Autonomía y Libertad, único compatible con el sentido de la dignidad defendido por el aparato de los derechos humanos. 


\section{Conclusiones}

Tras la sistematización realizada en el artículo, se encuentran los siguientes hallazgos:

- La constitucionalización del derecho penal, se presenta al relacionar las categorías desarrolladas por la Teoría del Delito con los principios constitucionales cuyo contenido determina la dimensión de lo criminalizable.

- La Constitución no establece un concepto de delito; sin embargo, los principios constitucionales relativos al derecho penal que ha desarrollado la jurisprudencia constitucional y convencional controlan lo que se puede considerar como delito en el sistema constitucional.

- La Teoría del Delito se constitucionaliza cuando sus categorías se interrelacionan con los principios constitucionales. En particular, la sistematización permite establecer tres parejas conceptuales: tipicidad-taxatividad, antijuridicidad-proporcionalidad y culpabilidad-dignidad.

- La pareja tipicidad-taxatividad expresa que solo hay tipicidad cuando hay taxatividad. Según esto, un tipo penal queda, por definición constitucional, sujeto a la exigencia de claridad y determinación. Una figura delictiva que muestra características como la indeterminación o la imprecisión en un grado excesivo o irrazonable, así sea formalmente válida por estar prevista en la norma penal, no puede contar como tal desde la perspectiva constitucional.

- La pareja antijuridicidad-proporcionalidad expresa que únicamente es legítimo criminalizar una conducta cuando se busca la finalidad de proteger un bien jurídico con anclaje constitucional, siendo, a su vez, la sanción una medida idónea y estrictamente necesaria para esa finalidad. Esta necesidad solo se agota cuando la conducta a criminalizar es antijurídica materialmente, esto es, cuando atenta contra el bien con anclaje constitucional. Si la conducta no representa este atentado antijurídico, su criminalización deviene desproporcionada, siendo una intervención excesiva en la libertad de la persona. Esta idea de la proporcionalidad brinda respaldo en un principio constitucional al postulado de exclusiva protección de bienes jurídicos bien conocido por la dogmática penal, de modo que su incumplimiento puede reclamarse como causa de inconstitucionalidad de la figura delictiva.

- El análisis de proporcionalidad ofrece una estructura argumentativa que permite reclamar la inconstitucionalidad de la criminalización en un sentido sustantivo o material por la falta de identificación de un bien jurídico, 
cuya protección justifique el ejercicio del poder punitivo. Asimismo, la estructura argumentativa de la proporcionalidad permite reclamar la inconstitucionalidad del tipo penal cuando la criminalización resulta innecesaria. Una criminalización resulta innecesaria en el marco constitucional cuando la conducta no resulta antijurídica en sentido material. En el Estado constitucional, la punición de conductas no antijurídicas aparece como desproporcionada.

- La pareja culpabilidad-dignidad supone que el respeto a la dignidad de la persona, entendido como el trato debido por parte del Estado, requiere un concepto material de culpabilidad fundado sustantivamente en una tesis fuerte sobre la libertad y la autodeterminación humana. Este fundamento material supone reconocer a todo ser humano como una persona libre y digna, a quien resulta admisible castigar únicamente por aquellas conductas antijurídicas que decide realizar libremente.

- La pareja culpabilidad-dignidad está también relacionada con el Principio de Proporcionalidad, lo que se hace patente en el escenario de la punibilidad. La culpabilidad funge como medida y como límite de la cantidad de pena que resulta proporcionado imponer a un autor concreto. El exceso o despro- porción de la sanción en este escenario resulta contrario a la dignidad.

A partir de estos hallazgos, se propone una definición constitucional según la cual un delito es toda conducta que resulta proporcional punir, porque reúne tres cualidades: a) es antijurídica, porque agrede un bien protegido constitucionalmente; $b$ ) es típica, porque encuadra en un tipo penal definido taxativamente; $y$ c) es culpable, porque es ejecutada libremente por una persona a la que se le reconoce dignidad.

Este concepto da las bases de desarrollo para una Teoría del Delito, que tiene en cuenta los principios constitucionales, atendiendo a que, en el Estado constitucional actual, el qué cosa cuenta como delito y forzosamente debe discutirse teniendo en cuenta dichos principios. La preeminencia de la Constitución permite sostener como argumento que la definición de delito dada por la Teoría del Delito dogmática-penal debe nutrirse -o ser controlada en su caso- por la definición constitucional.

Cabe insistir que estos principios constitucionales deben observarse durante el procedimiento judicial y, también, durante la labor legislativa. Particularmente, estos principios obligan al órgano legislativo al disponer las bases para una criminalización legítima. De esta manera, cuando el legislador establece figuras criminalizantes ilegítimas, se abre el camino 
de la justicia constitucional como vía para expulsar las figuras típicas que no son delitos constitucionalmente legítimos. La Teoría del Delito constitucionalizada es un modelo que da bases para que tanto la dogmática como la práctica penal impulsen por esas vías la contención del poder punitivo exacerbado.

\section{Referencias}

\section{Bibliografía}

Aguado Correa, T. (1999). El principio de proporcionalidad en el derecho penal. Edersa. http:// vlex.com/source/1308

Alexy, R. (1993). Teoría de los derechos fundamentales. Centro de Estudios Constitucionales.

----- (2016). Ponderación, control de constitucionalidad y representación. Juec. Pond. Argum. Instituto de Investigaciones Jurídicas de la UNAM, 1-18.

Alonso Álamo, M. (2009). Bien jurídico penal: más allá del constitucionalismo de los derechos. Est. Pen. Crimin., xxIx, 61-105. http://hdl. handle.net/10347/4144

Arroyo Zapatero, L. A. (1987). Fundamento y función del sistema penal: el programa penal de la Constitución. Rev. Juríd. Cast.-La M., 1, 97-110.

Bacigalupo, E. (1999). Principios constitucionales de derecho penal. Hammurabi.

Beccaria, C. (2015). Tratado de los delitos y de las penas. Universidad Carlos III de Madrid. http://hdl.handle.net/10016/20199

Carbonell, M., \& Sánchez Gil, R. (2011). ¿Qué es la constitucionalización del derecho? Quid
Iuris, 15, 33-55. https://revistas-colaboracion. juridicas.unam.mx/index.php/quid-iuris/ article/view/17397/15605

Carbonell Mateu, J. C.. (1999). Derecho penal: concepto y principios constitucionales. Tirant lo Blanch.

Comanducci, P. (2009). Constitucionalización y neoconstitucionalismo. Positiv. Juríd. Neoconst. Fundación Coloquio Jurídico Europeo, 85-121.

Cote-Barco, G. E. (2008). Constitucionalización del derecho penal y proporcionalidad de la pena. Universitas, 57(116), 119-151. https://revistas.javeriana.edu.co/index.php/vnijuri/ article/view/14562

Cruz Bolívar, L. (2001). La Constitución Política y la teoría del delito. Origen e implicaciones de una forma de interpretación de la dogmática. Der. Pen. Crim., 22(71), 105-114. https://revistas.uexternado.edu.co/index.php/ derpen/article/view/1096

Dondé Matute, J. (2012). Crítica a la teoría del delito: bases para su destrucción. En A. E. Nava Garcés, Dogmática penal y teoría del delito. Crítica y método (pp. 1-6). Porrúa/Universidad Anáhuac.

Donini, M. (2001). Un derecho penal fundado en la Carta Constitucional: razones y límites. La experiencia italiana. Rev. Pen., 8, 24-38.

Durán Migliardi, M. (2013). El planteamiento teleológico constitucional de la Escuela de Bologna y la obra de Franco Bricola como antecedentes históricos y metodológicos de la noción de derecho penal constitucional. Rev. 
Der. Univ. Cat. Norte, 20(2), 305-326. http://dx. doi.org/10.4067/S0718-97532013000200011

Dworkin, R. (1989). Los derechos en serio. Ariel.

Feijoo Sánchez, B. (Coord.) (2012). Derecho penal de la culpabilidad y neurociencias. Thomson Reuters/Civitas.

Fernández, J. Á. (2019). Bases para una reconstrucción estructural de los principios penales en el ámbito del control de constitucionalidad. Problema. An. Fil. Teor. Der., 13, 161-191. https://revistas.juridicas.unam. $\mathrm{mx} /$ index.php/filosofia-derecho/article/ view/13719/15016

Ferrajoli, L. (1995). Derecho y razón. Teoría del garantismo penal. Trotta.

García Ramírez,S. (2019). Decisiones penales en la Constitución mexicana. Rev. Fac. Der. Méx., 69(275), 141-182, http://dx.doi.org/10.22201/ fder.24488933e.2019.275-1.71462

Guastini, R. (2001). Estudios de teoría constitucional. Fontamara/Instituto de Investigaciones Jurídicas de la unam.

Hernández-Romo Valencia, P. (2020). Derecho constitucional penal mexicano. Tirant lo Blanch.

Inzunza Cázares, E. (2009). La exacta aplicación de la ley penal y el mandato de determinación. Instituto de Investigaciones Jurídicas de la unam/Escuela Libre de Derecho de Sinaloa.

Jakobs, G. (1996). Sociedad, norma y persona en una teoría de un Derecho penal funcional. Civitas.

---- (2004). Dogmática de derecho penal y la configuración normativa de la sociedad. Thomson Reuters/Civitas.
Náquira Riveros, J. (1995). Constitución Política y fundamento material del principio de culpabilidad. Rev. Ch. Der., 22(2), 189-200. http://www.jstor.com/stable/41609341

Ojeda Velázquez, J. (2005). Derecho constitucional penal (tomo I). Porrúa.

Ortega García, R. (2013). La constitucionalización del derecho en México. Bol. Mex. Der. Com., 137, 601-646. http://dx.doi.org/10.1016/ S0041-8633(13)71144-X

Quintero Olivares, G. (Dir.), \& Jaria i Manzano, J. (Coord.) (2015). Derecho penal constitucional. Tirant lo Blanch.

Rodríguez Mourullo, G. (2003). Delito, pena y Constitución. Rev. Juríd. Univ. Aut. Mad., 8, 311-330. http://hdl.handle.net/10486/3058

Roxin, C. (1981). Culpabilidad y prevención en derecho penal. Reus.

---- (2000). Política criminal y sistema del derecho penal. Hammurabi.

Sánchez Gil, R. (2017). El principio de proporcionalidad. Instituto de Investigaciones Jurídicas de la UnAM.

Suprema Corte de Justicia de la Nación (scjN) (2013). Dignidad humana, derecho a la vida y derecho a la integridad personal.

Vives Antón, T. S. (1996). La libertad como pretexto. Tirant lo Blanch.

Zaffaroni, E. R., Alagia, A., \& Slokar, A. (2002). Derecho penal. Parte general. Ediar.

\section{Jurisprudencia}

Corte Interamericana de Derechos Humanos, Caso Usón Ramírez vs. Venezuela, Sentencia de 20 de noviembre de 2009, Serie C, n. 207. 
Pleno, Tesis: P. LXV/2009, Semanario Judicial de la Federación y su Gaceta, Tomo xxx, diciembre de 2009, p. 8, Registro IUS: 165813.

Pleno, Acción de inconstitucionalidad 51/2018, Gaceta del Semanario Judicial de la Federación, Libro 77, agosto de 2020, Tomo II, p. 1213, Registro IUS: 29427.

Primera Sala, Tesis: 1a. CCXII/2011 (9a.), Semanario Judicial de la Federación y su Gaceta, Libro II, noviembre de 2011, Tomo 1, p. 194, Registro IUS: 160710.

Primera Sala, Tesis: 1a. CCXIII/2011 (9a.), Semanario Judicial de la Federación y su Gaceta, Libro II, noviembre de 2011, Tomo 1, p. 194, Registro IUS: 160709.

Primera Sala, Tesis: 1a. CCXI/2011 (9a.), Semanario Judicial de la Federación y su Gaceta, Libro II, noviembre de 2011, Tomo 1, p. 210, Registro IUS: 160642.

Primera Sala, Tesis: 1a. CCX/2011 (9a.), Semanario Judicial de la Federación y su Gaceta, Libro II, noviembre de 2011, Tomo 1, p. 212, Registro IUS: 160640.

Primera Sala, Tesis: 1a./J. 19/2014 (10a.), Gaceta del Semanario Judicial de la Federación, Libro 4, marzo de 2014, Tomo i, p. 374, Registro IUS: 2005883.

Primera Sala, Tesis: 1a. CCCIX/2014 (10a.), Gaceta del Semanario Judicial de la Federación, Libro 10, septiembre de 2014, Tomo I, p. 590, Registro IUS: 2007342.

Primera Sala, Tesis: 1a./J. 37/2016 (10a.), Gaceta del Semanario Judicial de la Federación, Libro 33, agosto de 2016, Tomo II, p. 633, Registro IUS: 2012363.
Primera Sala, Tesis: 1a./J. 10/2019 (10a.), Gaceta del Semanario Judicial de la Federación, Libro 63, febrero de 2019, Tomo I, p. 493, Registro IUS: 2019365.

Primera Sala, Amparo en revisión 547/2018, Gaceta del Semanario Judicial de la Federación, Libro 63, febrero de 2019, Tomo I, p. 411, Registro IUS: 28352. 